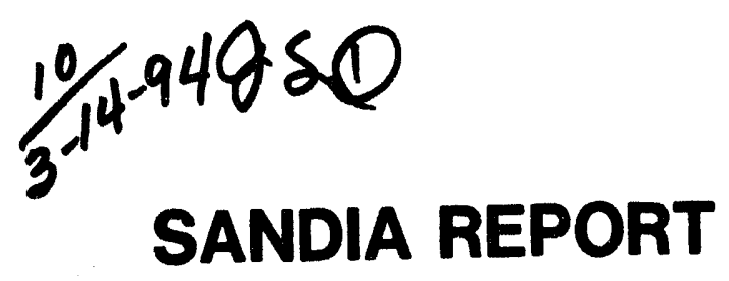

SAND92-2416 - UC-742

Unlimited Release

Printed February 1994

\title{
Electrostatic Discharge Testing of Propellants and Primers
}

\author{
R. Bruce Berry
}

Prepared by

Sandla Matlonal Laboratorbe

Albuquerquo, Now Moxlco 87185 and Luvormore, Callfornile 94850

for the Unitod states Dopartment of Enorey

under Contract DE-ACO4-84AL85000 
Issued by Sandia National Laboratories, operated for the United States Department of Energy by Sandia Corporation.

NOTICE: This report was prepared as an account of work sponsored by an agency of the United States Government. Neither the United States Government nor any agency thereof, nor any of their employees, nor any of their contractors, subcontractors, or their employees, makes any warranty, express or implied, or assumes any legal liability or responsibility for the accuracy, completeness, or usefuiness of any information, apparatus, product, or process disclosed, or represents that its use would not infringe privately owned rights. Reference herein to any specific commercial product, process, or service by trade name, trademark, manufacturer, or otherwise, does not necessarily constitute or imply its endorsement, recommendation, or favoring by the United States Government, any agency thereof or any of their contractors or subcontractors. The views and opinions expressed herein do not necessarily state or reflect those of the United States Government, any agency thereof or any of their contractors.

Printed in the United States of America. This report has been reproduced directly from the best available copy.

Available to DOE and DOE contractors from Office of Scientific and Technical Information PO Box 62

Oak Ridge, TN 37831

Prices available from (615) 576-8401, FTS 626-8401

Available to the public from National Technical Information Service

US Department of Commerce

5285 Port Royal Rd

Springfield, VA 22161

NTIS price codes

Printed copy: A03

Microfiche copy: A01 
SAND92-2416

Unlimited Release

Printed February 1994
Distribution

Category UC-742

\title{
ELECTROSTATIC DISCHARGE TESTING \\ OF
}

PROPELLANTS AND PRIMERS*

\author{
R. Bruce Berry \\ Explosive Projects and Diagnostics Department \\ Sandia National Laboratories \\ Albuquerque, NM 87185-0327
}

\begin{abstract}
This report presents the results of testing of selected propellants and primers to Electrostatic Discharge (ESD) characteristic of the human body. It describes the tests and the fixturing built to accommodate loose material (propellants) and the packed energetic material of the primer. The results indicate that all powders passed and some primers, especially the electric primers, failed to pass established requirements which delineate insensitive energetic components. This report details the testing of components and materials to four ESD environments (Standard ESD, Severe ESD, Modified Standard ESD, and Modified Severe ESD). The purpose of this study was to collect data based on the customer requirements as defined in the Sandia Environmental Safety \& Health (ES\&H) Manual, Chapter 9, and to define static sensitive and insensitive propellants and primers.
\end{abstract}

"The work described in this report was performed by Sandia National Laboratories for the United States Department of Energy under contract DE-AC04-94AL85000. 


\section{ACKNOWLEDGMENTS}

The author would like to thank the following for their contributions to this project:

John Lanoue (2654), who put together a preliminary fixture design; Roy Dickey (TAD Contract Services), who drew and refined the design; Daniel Dow and Ward Engebrit (Ktech Corporation), who machined the fixture; and John Barnum and Marvin Morris (2753), for their technical review of this manuscript and valuable suggestions. 


\section{CONTENTS}

\section{Section}

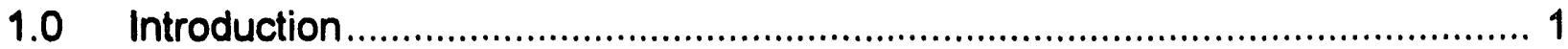

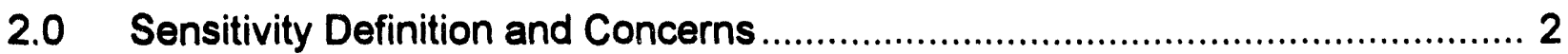

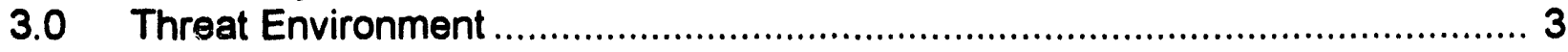

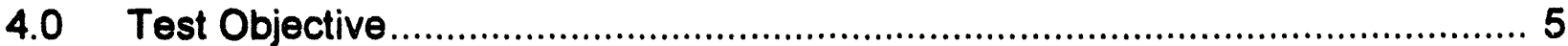

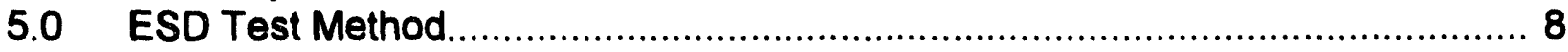

6.0 Test Configurations and Test Fixtures........................................................ 10

6.1 Powder Fixture Description and Associated Concerns.................................. 10

6.2 Percussion Primer Fixture Configurations and Concerns.............................. 19

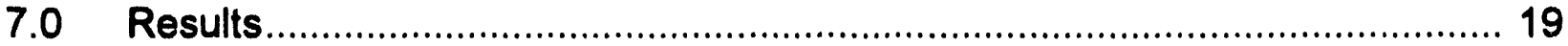

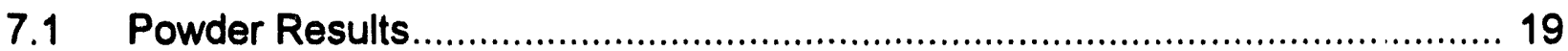

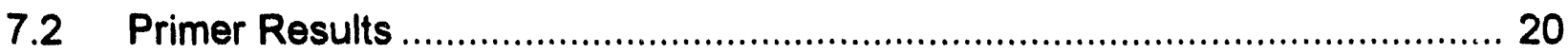

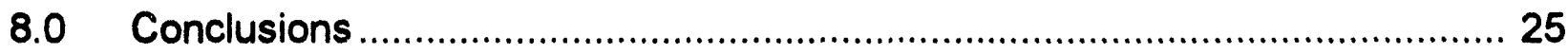

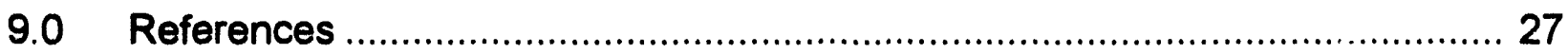

Appendix A

Distribution

\section{Tables}

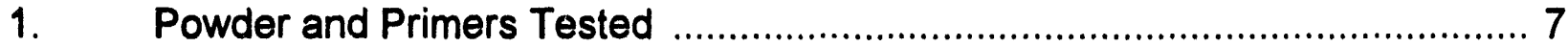

2. ESD Sensitivity Results for Powders ......................................................... 21

3. Neyer Sensitivity Results/Large Rifle Electric and $30 \mathrm{~mm}$ Percussion

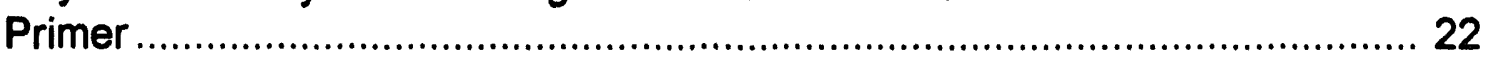

4. Neyer Sensitivity Results/20 mm Electric, Large Rifle Electric, and $30 \mathrm{~mm}$ Percussion Primers ........................................................... 23

5. ESD Neyer Sensitivity Results/30 mm Percussion Primer, Severe Human Body Tester ............................................................................ 23

6. ESD Neyer Sensitivity Results/Large Rifle Electric Primer, Severe Human Body Tester ......................................................................... 24

7. ESD Neyer Sensitivity Results/20 mm Electric Primer, Standard Man Tester

8. ESD Neyer Sensitivity Results/30 mm Percussion Primer, Standard Man Tester

9. ESD Neyer Sensitivity Results - Large Rifle Electric Primer, Standard Man Tester 


\section{CONTENTS CONTINUED}

\section{Fiqures}

1. Equivalent Circuit and Resulting Voltage Waveform for Standard Man ESD Test

2. Equivalent Circuit and Short-Circuit Current Waveform for Sandia Severe Human Body ESD Test

3. ESD Test Fixture and Discharge Electrode ........................................ 11

4. Primer ESD Test Configuration ............................................................. 13

5. ESD Test Fixture with Loose Powder ........................................................ 15

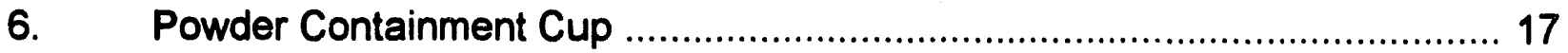




\section{Section 1: Introduction}

The electrostatic discharge testing of thirty different propellants (powders) and ten primers of various caliber was conducted by Department 2654 (Explosive Projects and Diagnostics) as a result of a request from Departments 1443 (Experimental Impact Physics Department), and 2761 (Environmental Test Department). For these tests, the propellants included single and double based powders. Single base propellants consist primarily of nitrocellulose, while double base propellants contain nitrocellulose and nitroglycerine.

Percussion primers (also known as "caps") serve as primers for propellant charges. In mechanical percussion caps, a friction sensitive or impact sensitive priming charge (containing, for example, mercury fulminate with chlorates or lead trinitroresorcinate with tetrazene) is ignited by the mechanical action of a firing pin. The electric primers are similar to the percussion primers, but the anvil has been replaced by an electric initiating circuit. This circuit heats the primer charge when power is applied. These devices are intentionally designed to be sensitive, requiring little electrical energy to initiate.

These materials are currently used at the Shock Thermodynamics and Applied Research (STAR) facility for the initiation of single-stage and two-stage powder guns. They are also used for custom test development and reloading at the Rocket and Dynamic Test Complex. During the development of their specific safety documentation, based on the Sandia Environmental Safety \& Health (ES\&H) Manual1] requirements (Chapter 9E), the question of human body electrostatic discharge (HBESD) sensitivity of these materials needed to be addressed. Review of available manufacturer data sheets did not provide sufficient information to resolve the issue. The test program described in this report was developed and executed to provide insight into the HBESD sensitivities of the powders and primers. Appendix A contains a copy of the test plan used for this investigation.

It was decided to test the powders and primers to the two types of ESD pulses available. The two ESD sources chosen were the Sandia Standard Man Model[2] and the Sandia Severe Electrostatic Discharge Model[3]. Other (i.e., not human body types) ESD threats were not considered. Further work would be needed to bound the possible threat levels and then develop an appropriate simulated threat waveform.

This report presents the results of the testing and provides a rank-order guidance of ESD sensitivities that may exist when handling propellants and primers. It describes the tests and fixturing built to accommodate loose propellants and the packed energetic material of the primer. It details results showing that all thirty powders passed both types of ESD pulses and the failure of some primers to pass established requirements to be classed as insensitive components. 
The following seven sections provide the technical description and presentation of results: Section 2, Sensitivity Definition and Concerns, discusses how the sensitivity of a primer of powder was defined and identifies safety concerns when using this sensitivity definition; Section 3, Threat Environment, discusses the HBESD threat environments chosen for this investigation; Section 4, Test Objective, identifies objectives based on sensitivity definition and chosen environments; Section 5, ESD Test Method, reviews the test methods; Section 6, Test Configurations and Test Fixtures, presents details on the test configurations and required test fixtures; Section 7, Results, contains the ata from HBESD sensitivity tests performed on the powders and primers; and Section 8, Conclusion, draws conclusions from the data and identifies safety concerns.

\section{Section 2: Sensitivity Definition and Concerns}

The sensitivity of energetic or explosive devices and materials to threat environments (mechanical shock, heat, electrical discharge) can be seen in terms of its response, from degradation in reliability, to deflagration (burning) or detonation. For this investigation, sensitivity is defined as an observable change in the physical appearance of the material or device after the application of a simulated HBESD stress. The primers clearly showed when they fired (go/no go); however, powders (propellants) were more difficult to evaluate.

When an electrical discharge in a powder results in a spark or arc, physical responses occur that can distort the interpretation of the test results and sensitivity classification. During formation of the spark discharge, a high-current-density channel is formed between two electrodes. The current flowing through this channel results in very high temperatures and pressures which, in turn, generate a pressure shock pulse that can be heard as a pop or bang depending on the energy transferred through the channel. Additionally, it may be of sufficient intensity to scatter loose powder away from the test area where the discharge is occurring, and prevent ignition of the powder. This scenario, which could be inferred as a sensitivity, is a test variable that must be controlled. Determining the sensitivity of loose powders requires defining the reaction that identifies sensitivity. It also includes identifying and controlling the variables that can influence the sensitivity.

The evaluation of the sensitivity of the material under test may be influenced by: configuration, density, quantity of material, temperature, humidity, and electrode configuration. Ideally, sensitivity tests are designed to duplicate or approximate the actual use conditions; however, this is not always possible and was not possible for this investigation. Given that only small samples were available for testing and that there are no universally accepted test standards for testing loose powders, a semiconfinement test configuration was chosen to prevent the powders from being scattered away from the test electrodes. The test configurations developed for powders are 
described in detail in Section 6. Failure (for purposes of these tests) was defined as a sample that had significant damage, such as a burn of the powder or a firing of the primer. Burn of a powder was further defined as a complete burn of the powder, and not merely a charring or puff of smoke. The samples were inside a firing chamber and could not be viewed during testing, so only post-test observation could be made. This determination was based on the definition in Sandia Specification SS302365-000[2] for electrostatic sensitivity, which defines a failure as ". . any device which initiates when subjected to the test pulse."

In this investigation, an observed sensitivity was correlated to ESD simulator (tester) parameters: (1) charging voltage, the initial voltage at which the capacitors in the simulator are raised prior to discharge, and (2) total energy, the energy stored in the simulator capacitors at the desired charge voltage.

Because powder sensitivity may be influenced by environmental conditions and use configurations, the sensitivity for an actual situation may be more or less than that identified in the small quantity, single-configuration, testing described in this report. Any operations involving loose powders should be assessed with these possible dependencies in mind.

\section{Section 3: Threat Environment}

The HBESD environment has been investigated[4] at least twice over the past 20 years at Sandia National Laboratories (SNL). In 1973, a SNL Working Group required that all future explosive devices must be designed to withstand a simulated human body electrostatic discharge. At that time, the best realization of the HBESD threat was a 600-picofarad (pF) capacitance charged to 20 kilovolts (kV) and discharged through a series resistance of 500 ohms into an explosive device. This representation of the HBESD threat is known as the Standard Man Model. Figure 1 illustrates the equivalent circuit and the resulting waveform for a $500 \mathrm{ohm}$ resistive load. This requirement was documented in Sandia Specification SS302365-000[2], which identifies tester and test requirements for this particular ESD model.

In 1988, the human body ESD characteristics was re-investigated by R. J. Fisher[5]. This investigation resulted in an equivalent HBESD model referred to as the Sandia Severe HBESD model. 


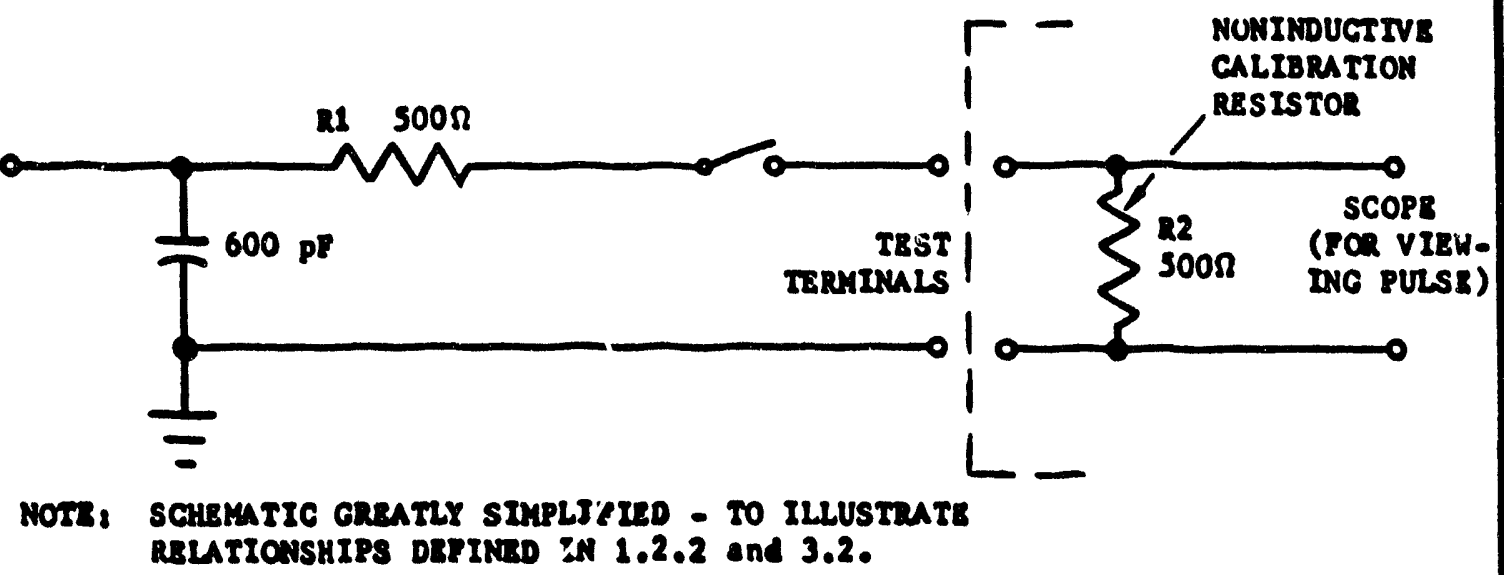

PIOURE 1 - IRST CIRCUIT UITH CALIARATION RESISTOR

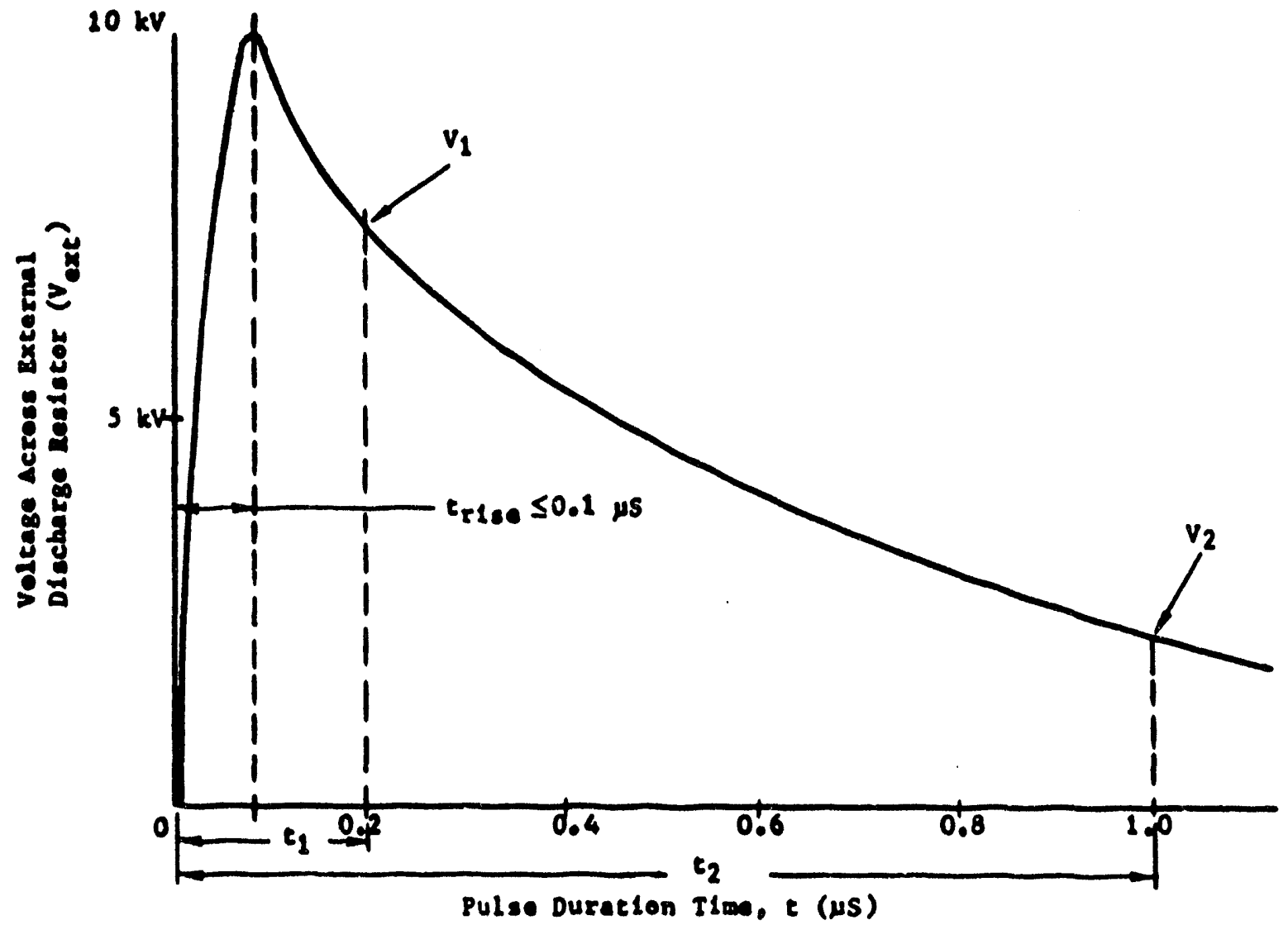

PIGURE 2 - OBSERVED DISCHARGB CURVE ACROSS EXTERML RESISTO2

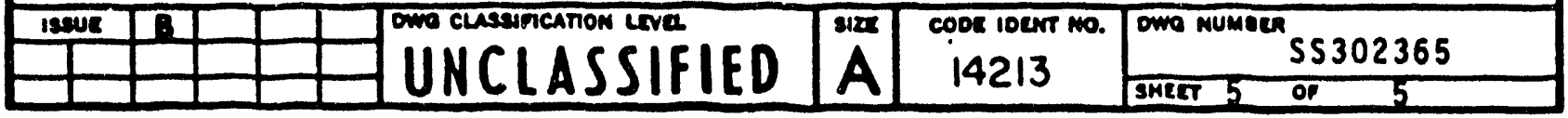

Figure 1.

Equivalent Circuit and Resulting Voltage Waveform for Standard Man ESD Test (SS302365-000) 
This model is considered to be a better HBESD representation and a slightly more severe threat than identified in the Sandia Specification for the Sandia Standard Tester, human body (Sandia Specification SS302365-000). Figure 2 illustrates the equivalent circuit model and resulting short-circuit current waveform for this new model. The details and rationale for the new model are provided in The Electro-Static Discharge Threat Environment Data Base and Recommended Baseline Stockpile-toTarget Sequence Specifications[5]. This model has also been accepted as a standard requirement for explosive testing at Sandia and is documented in the Sandia Specification for the Sandia Severe Human Body Tester for Electro-explosive Devices, SS392498-000[3].

Although the two models are similar in total stored energy at the specified voltage levels ( 120 millijoules at $20 \mathrm{kV}$ for the Standard Man and 128 millijoules at $25 \mathrm{kV}$ for the Severe), the discharge wave shapes are quite different. Thus, sensitivity rankings based on these two models may not be identical. In general, if a material or device initiates at a level less than or equal to the standard Severe HBESD test level (128 millijoules), it is prudent that it be considered sensitive when exposed to a human body ESD environment. Sensitivities identified with the Standard Man ESD environment are useful for comparison to other materials or components previously tested to this requirement.

Section 4: Test Objective

The primary objective of this investigation was to identify and document potential sensitivities of the powders and primers to HBESD (Table 1). This objective is supported by requirements in Section 9 of the ES\&H Manual To determine this classification, the Manual requires that testing in accordance with Sandia Specification SS302365-000[2] be performed. The Manual also requires that the tests be carried out using an accepted statistical approach .

The ES\&H Manua/11], in Section 9, Page 9E-4, defines static sensitive materials as " . . those which exhibit a discernible reaction when subjected to the test conditions described in S\$302365-000." This specification is usually applied to electro-explosive devices and does not specifically mention energetic materials (i.e., primers and propellants). Another area of confusion lies in the definition of "discernible reaction." This may mean a pop, bang, or simply smoke. The shock generated by the electrical discharge itself may be sufficient to produce a pop; however, it does not mean that the sample is sensitive. 


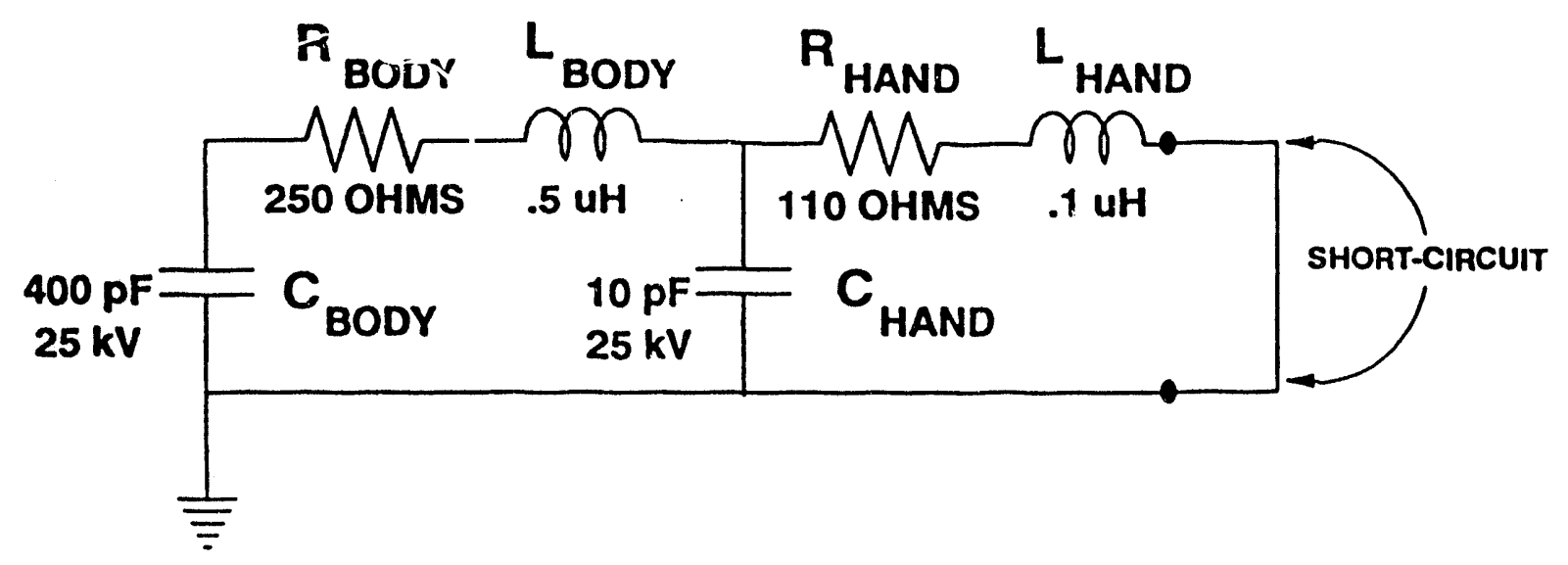

Severe Human Body ESD Model Equivalent Circuit
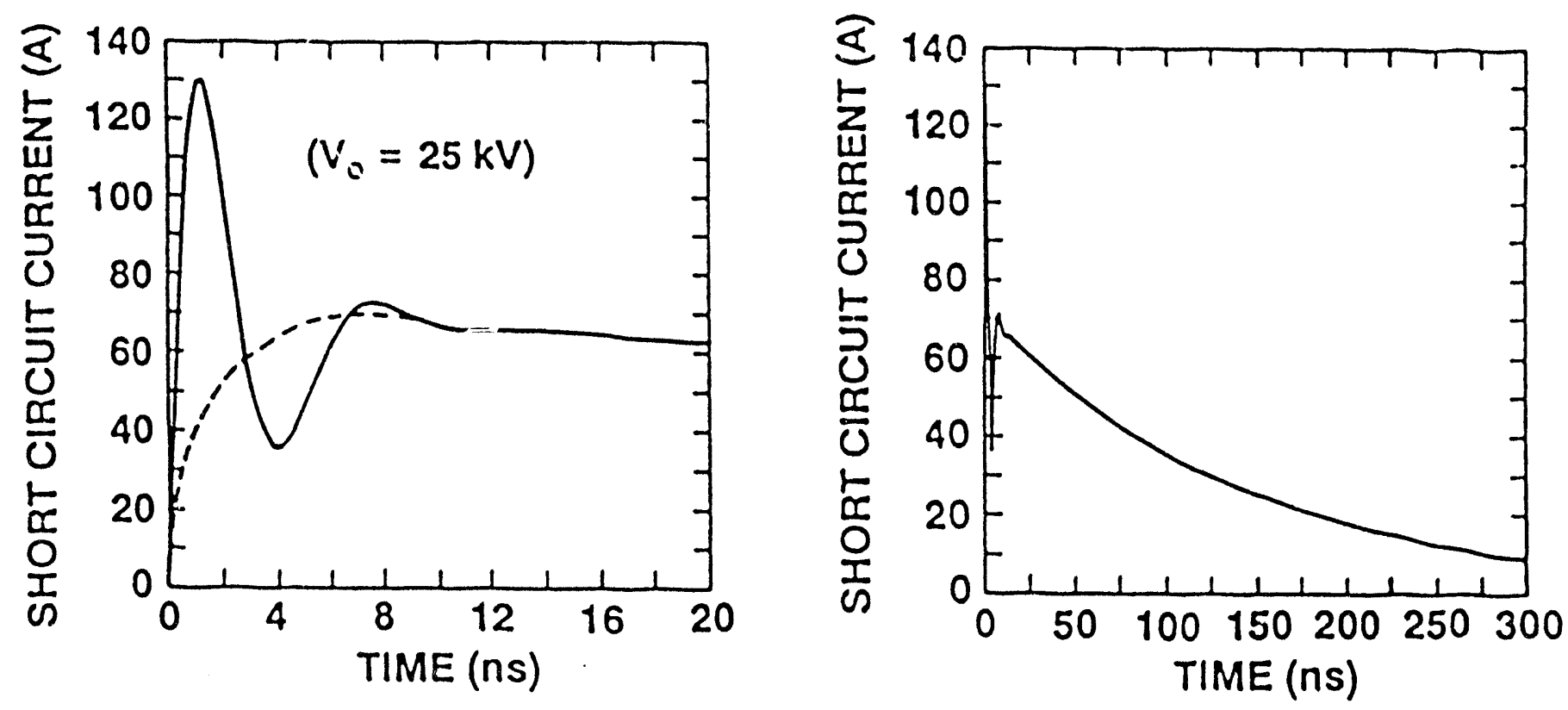

Short-Circuit Current with the Equivalent Circuit Charged to $25 \mathrm{kV}$

Figure 2.

Equivalent Circuit and Short-Circuit Current Waveform for the Sandia Severe Human Body ESD Test (SS392498-000) 
Table 1.

Powders and Primers Tested

POWDERS TESTED

$20 \mathrm{~mm}$

$3^{\prime \prime}-50$

$800 \mathrm{X}$

BKN03

DUPONT SR47:59

FFFF

H4831

H870

HERCULES BLUE DOT

HERCULES BULLSEYE

HERCULES GREEN DOT

HERCULES HERCO

HERCULES RED DOT

HERCULES UNIQUE

IMR4064

IMR4198

IMR4320

IMR4350

IMR4895

SS255 LOT 97

W237 X4599

WA20 LOT 36

WC237 LOT X4600

WINCHESTER 2400

WINCHESTER 296

WINCHESTER 540

WINCHESTER 571

WINCHESTER 748

WINCHESTER 760

WINCHESTER 785
PRIMERS TESTED

$30 \mathrm{~mm}$ BOOSTER

$20 \mathrm{~mm}$ ELECTRIC

$30 \mathrm{~mm}$ PRIMER

50 CALIBER

LARGE PISTOL

LARGE RIFLE

LARGE RIFLE ELECTRIC

SHOTSHELL

SMALL PISTOL

SMALL RIFLE 
If a bang or smoke is produced, the sample may be sensitive. The ES\&H Manual also states that "... Statistical methods should be employed and a sample population should be tested. Some of the devices should be tested at voltages less than the maximum in case there is more than one mode of initiation. Some of the devices should be tested repeatedly in case sensitization occurs." It goes on to state that static sensitive items "... which do not pass the criteria for static-sensitive explosives or static sensitive devices, or which are untested, must be treated as static sensitive." This criteria was the basis for the test plan (Appendix A).

To ensure a statistical method, a Neyer Statistical Testing Method[6] was employed for the tests. This method has the advantage of determining the threshold reaction voltage with the minimum number of samples.

The powders and primers were tested using the Sandia Standard Man (STD MAN) and the Severe Human Body Model Tester (SEVERE) using two different configurations: standard and extended. The Standard Man tester in the standard configuration is $20 \mathrm{kV}$ using a 600 picofarad capacitor, for a total stored energy of 120 millijoules. The extended configuration is $24.5 \mathrm{kV}$ using a 1200 picofarad capacitor for a total stored energy of 360 millijoules. The Severe tester is normally charged to $25 \mathrm{kV}$ using a 410 picofarad capacitor, for a total stored energy of 128 millijoules. The extended configuration consists of charging to $30 \mathrm{kV}$ using a 410 picofarad capacitor for a total stored energy of 185 millijoules.

To assess the HBESD sensitivity of the powders and primers, and to comply with the ES\&H Manual guidelines, tests were performed by exposing the individual powder and primer samples to electrical discharges that simulated the Standard Man and Severe Human Body ESD environmental threats. In cases where sensitivities were observed, the Neyer statistical sensitivity test method was used. This method determines the $50 \%$ Fire/No-Fire threshold and minimizes the number of samples that are required to obtain this parameter. The $50 \%$ Fire/No-Fire threshold is defined where $50 \%$ of the samples will initiate or burn when subjected to the identified stress.

\section{Section 5: ESD Test Method}

The ESD simulation sources used to assess the sensitivity of the powders and primers were the Standard Man Tester (SMT), as called for in the ES\&H Manual, and the Sandia Severe Human Body ESD Tester (SSET). The SMT and SSET are normally operated at a maximum voltages of $20 \mathrm{kV}$ (Sandia Specification SS302365-000[2]) and $25 \mathrm{kV}$ (Sandia Specification SS392498-000[3]), respectively. As described above, these voltages were extended to 24.5 and $30 \mathrm{kV}$, respectively, in an attempt to induce a response when none was observed at 20 or $25 \mathrm{kV}$. 
The test procedure for assessing the sensitivity of the powders and primers involved applying the stress produced by the desired source to the test sample (powder or primer) via a specially constructed test fixture. Additional details on the fixtures are provided in Section 6. For all test samples, the current delivered to the test sample was monitored with a current viewing resistor (CVR). This measurement was used only to assure that a pulse was delivered to the test object; it was not used for any quantitative analysis.

Sensitivity threshold levels were determined using a bounding approach. The first pulse applied to a test sample was at the specified test voltage of 20 or $25 \mathrm{kV}$ for the SMT and SSET, respectively. When a response was observed, the Neyer statistical testing method vias used.

A powder or primer that passed the standard ESD tests was next subjected to the maximum energy available from each of the two simulators. New samples were used for this testing to eliminate any influences from the previous pulse. The two simulators were reconfigured to provide the maximum possible stress levels. On the Standard Man Tester the capacitor was changed to a 1200 picofarads and the voltage level was increased to 24.5 kilovolts to achieve 360 millijoules of stored energy. On the Severe Tester the voltage level was brought to a maximum of 30 kilovolts to discharge a peak stored energy of 185 millijoules. If the devices failed the maximum ESD test, then a Neyer statistical test was performed. If the devices did not fail, no further testing was done.

Changing the capacitor in the Standard Man model did not significantly influence the wave shape of the pulse delivered. The capacitors were obtained from the same manufacturer and all were ceramic, precision-type, capacitors. The major differences between the two testers is that the Standard Man tester simulates only a body discharge with a relatively slow rise time (1000 nanoseconds). The Severe model simulates a hand discharge with a fast ( 1 nanosecond) rise time followed by a body discharge with a slower rise time; see Figure 2. It can be inferred that the thresholds are dependent on not only the total energy delivered, but the rate at which the energy is delivered.

Powders are extremely difficult to test with meaningful results. The containment configuration, density and quantity (among other parameters) of material will affect the results. The tests descrined provide information relative to the particular configuration; it may have little meaning to an actual configuration of use. The material may be more or less sensitive for a given amount of confinement and the same holds true for changes in density and quantity. 
Section 6: Test Configurations and Test Fixtures

Although two different simulators were used to test powders and primers, the test configurations were similar for all cases. The test fixture used for the powders and the primers consisted of an adapter to the simulator output and an adjustable air-gap discharge electrode arrangement. The fixture is shown in Figure 3 . The positive source electrode consisted of a dressmaker's pin (1.05 inches long, 0.025 -inch diameter radius tip) attached to a micrometer, which allowed precise positioning of the discharge needle above a steel base plate. The base plate was 0.75 inch in diameter and 0.5 inch thick and served as the return electrode.

Connection of fixtures and the propellants and powders themselves result in the addition of inductive and capacitive parasitics that can influence the stress applied to the test object. For the described test configurations, the connection leads were kept short to minimize, but not eliminate, these influences. There was no attempt to characterize these parasitics or predict their influence on the sensitivity levels.

\section{Section 6.1: Powder Fixture Description and Associated Concerns}

Initial testing of the powders confirmed that the shock pulse generated by the electrical discharge resulted in scattering the powder away from the test electrodes. Figure 5 shows that loose powder configuration. To eliminate scattering, a plastic powder confinement cup was used. Figure 6 shows the powder contained in the cup and the position of the electrodes. The cup is a plastic tube, approximately 0.5 inch long and 0.25 inch in diameter, that is glued to an insulating washer. The washer stabilizes the cup on the base plate and allows the powder to make contact with the steel base plate. The cup was filled with the desired powder sample and leveled with the top of the tube, but not packed down. The needle electrode was placed directly into the cup and powder at a distance of 50 milli-inches above the base plate surface. This needle-base-plate distance was used in previous ESD tests performed by the Naval Ordnance Laboratory[7].

In actual use, the powders evaluated in this test would presumably be used in bulk form and not confined. In this case, a spark might scatter the powder, thus mitigating the threat. Another possible scenario might be a spark discharge delivered to a large quantity of powder. In this case, the large quantity of the powder might be selfconfining and a reaction could occur. The semi-confinement test configuration used was the best small-quantity realization of the actual use configuration that could be developed. However, there was no attempt to quantify other parameters (temperature, quantity, density, humidity, electrode configuration) that might influence the sensitivity. Thus, not knowing these influences, sensitivities in actual use could be more or less than those identified here. 


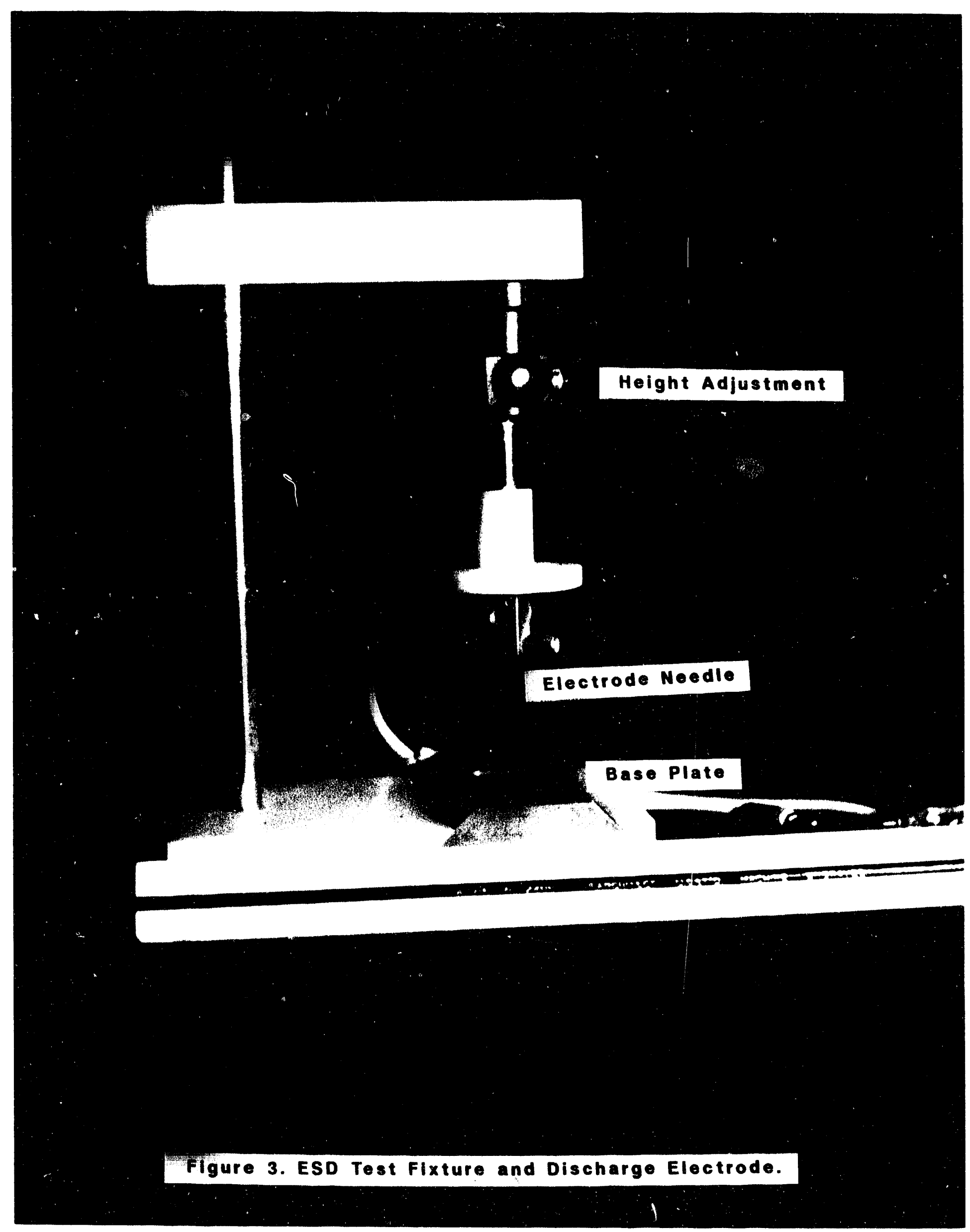




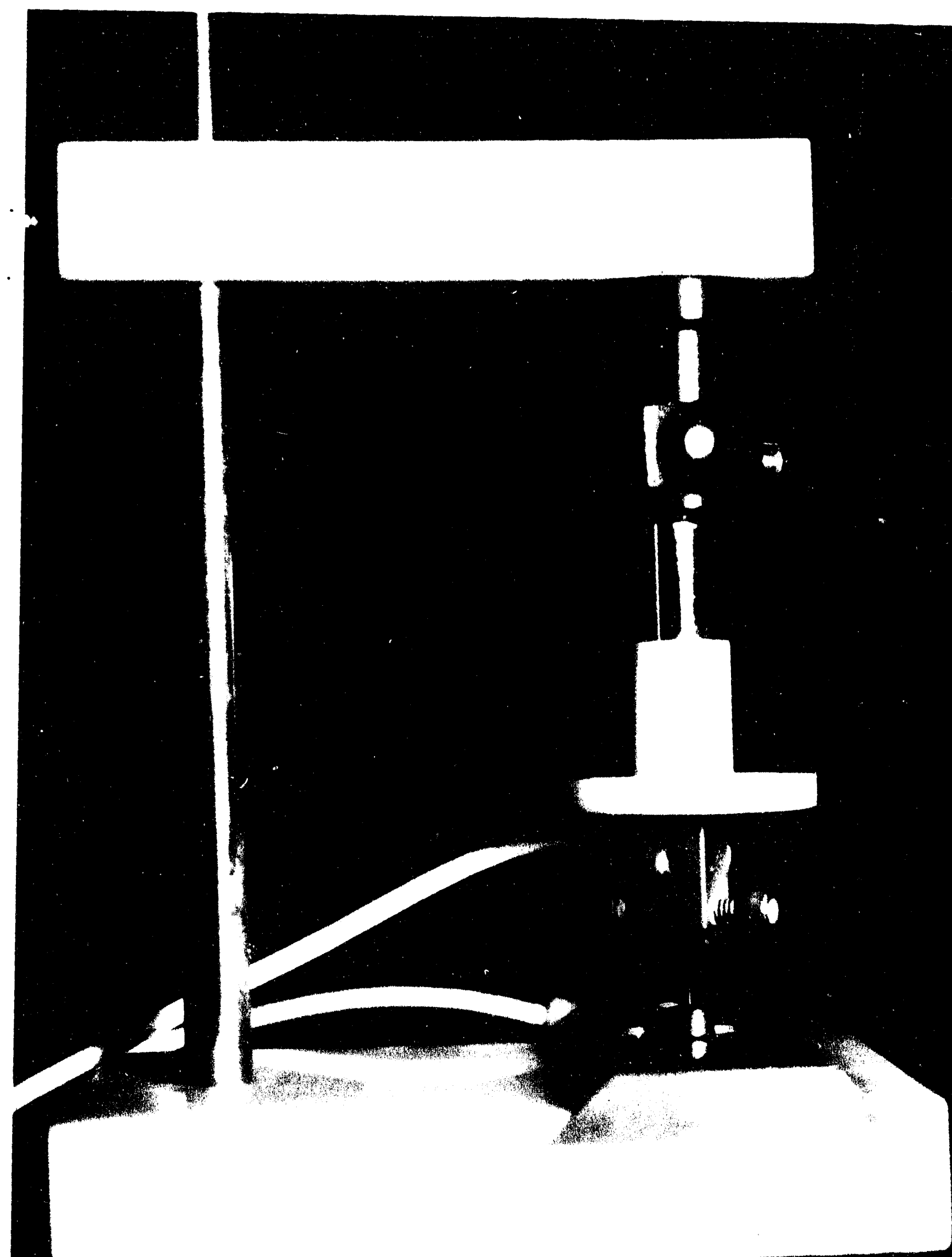

Figure 4. Primer ESD Test Configuration. 


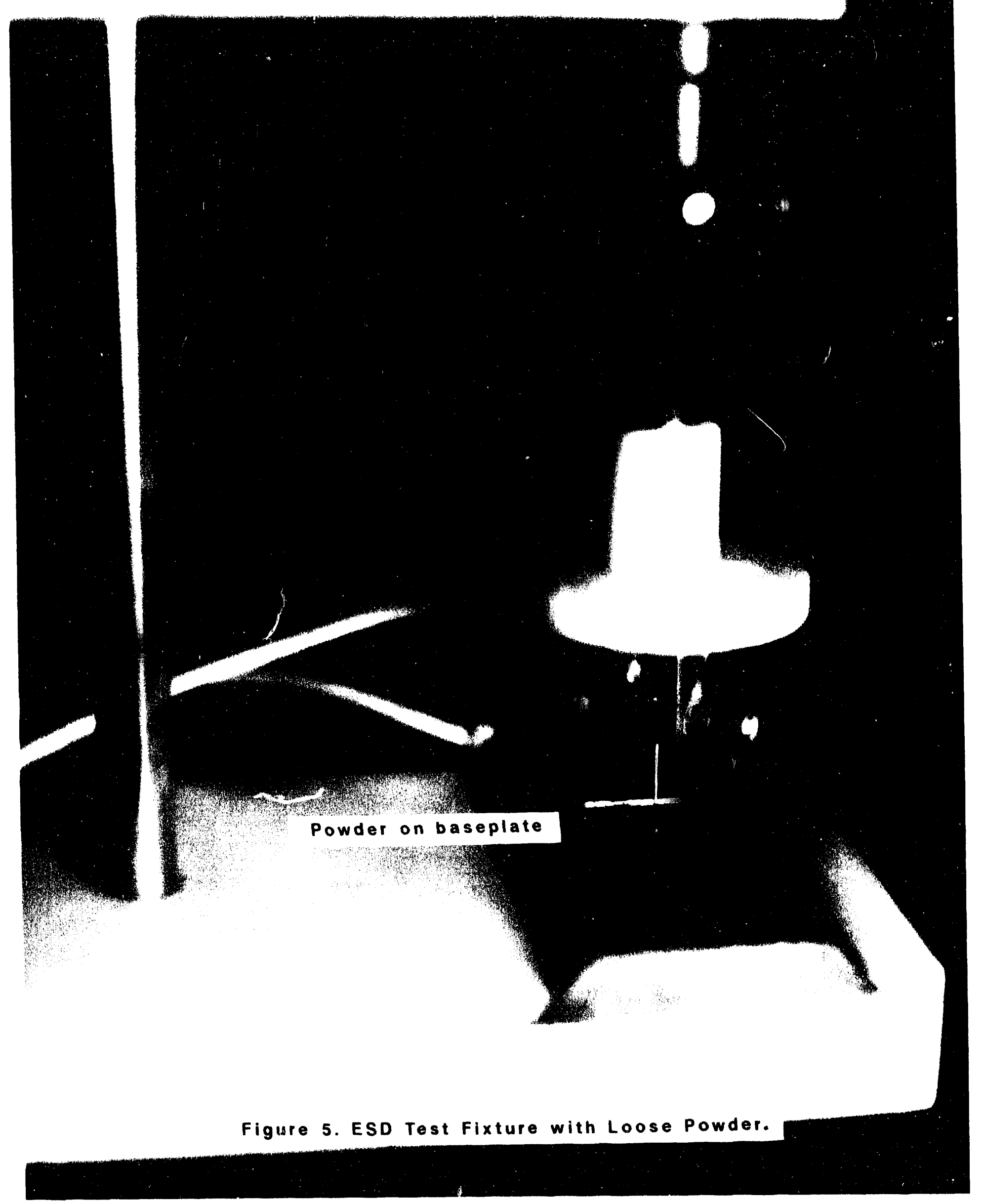

$-15 / 16-$ 


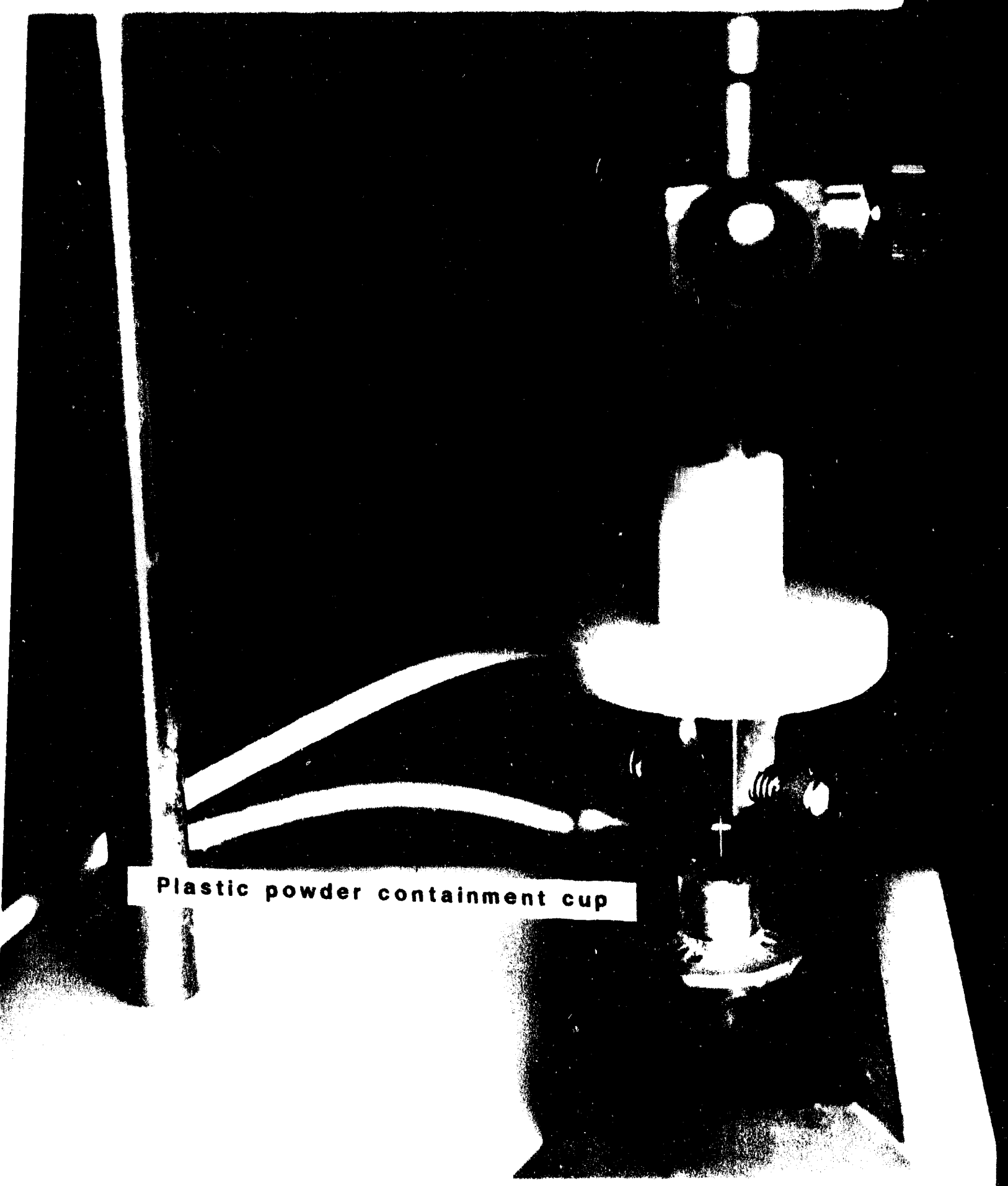

Figure 6. Powder Containment Cup.

$-17 / 18-$ 
Section 6.2: Percussion Primer Fixture Configurations and Concerns

The test configuration used for the percussion primers was very similar to the powder fixture. In this case, the primer was placed on the steel base plate and the discharge needle was inserted through the flash hole into the primer, taking care not to short the electrode to the primer case (Figure 4). No plastic cup was used. Some of the primers were supplied installed in shells. In these cases, the primer was removed from the shell. In the case of the 50-caliber shell, the primer could not be completely removed. To allow access to the flash hole, the shell was machined to expose the primer. Placing the needle electrode through the flash he'e ensured that the ESD stress was delivered to the interior of the primer. In actual use, it is unlikely that an ESD stress would be delivered in a similar fashion. The tests, performed by discharging the ESD simulator into the interior of the primer, served to identify the sensitivity level of the material used in the primer and not necessarily the primer (as an integral unit) itself.

\section{Section 7: Results}

The data presented in this report is given in terms of observed evidence of initiation as a function of total energy stored in the tester capacitive discharge circuits and the tester charging level. These parameters are useful in ranking the sensitivity of the powder or primer given the specified ESD environment and configuration. The total energy values presented must not be confused with energy delivered to the test object. As shown in Figures 1 and 2, the energy must first pass through pulse shaping elements (resistors and inductors); the resistance in these elements will absorb some percentage of the total energy. The energy actually absorbed by the test object will be a function of the test object and other circuit resistances. While the circuit resistances are well defined, the test sample resistance will change as a function of time; thus, quantifying the energy absorbed by the test sample is difficult. To do so would require simultaneous measurement of the voltage across and current through the test sample. Accurato determination of these parameters in an ESD environment is difficult and requires sophisticated, specially designed, and calibrated monitors that were not available at the time these tests were conducted.

\section{Section 7.1: Powder Results}

All of the powders were exposed to the standard and extended energy configurations. There were no indications of sensitivities for any combination of powder and simulator configuration and, as a result, Neyer sensitivity tests were not performed. These results indicate that the powders are not sensitive to the HBESD stress environment, at least for the given configuration of small quantities and semi-confinement. Only one 
sample was tested for each configuration, thus, the results cannot be defended in terms of a statistical assessment. However, given that no sample initiated, there is a basis for considering that these materials are HBESD insensitive. To statistically confirm this, additional testing is required.

\section{Section 7.2: Primer Results}

Primers were tested with the standard and extended configurations for each simulator. These tests resulted in several initiations as shown in Table 2. In two cases, a complete set of tests was not performed (indicated by an asterisk in the table) because the primers initiated at all the lower levels and the available samples were limited.

In one case (small pistol primer), there was an initiation for the extended severe human body configuration but not for the other configurations. To confirm this sensitivity, three additional samples were stressed and there were no signs of initiation. This response suggests that this device may have a sensitivity close to the maximum output available from the SSET ( $30 \mathrm{k} V)$. This response may have been due to a material sensitivity or an anomaly in the manufacturing of this component. While this may be of concern, the fact that there were no initiations observed for the other configurations suggests this primer is reasonably insensitive to the specified standard test levels. To resolve this issue more samples must be tested.

The primers that did not initiate in response to the applied stresses are the $30 \mathrm{~mm}$ booster, 50 caliber, large pistol, large rifle, shotshell, and small rifle. Like the powders, these results suggest that these devices are insensitive to the HBESD environment; however, only one sample was tested, thus, statistical significance cannot be inferred from the data. 
Table 2.

ESD Sensitivity Results for Primers

(Standard and Extended Test Levels)

\begin{tabular}{|c|c|c|c|c|}
\hline $\begin{array}{l}30 \mathrm{~mm} \text { BOOSTER } \\
20 \mathrm{~mm} \text { ELECTRIC } \\
30 \mathrm{~mm} \text { PRIMER } \\
50 \text { CALIBER } \\
\text { LARGE PISTOL } \\
\text { LARGE RIFLE } \\
\text { LARGE RIFLE ELECTRIC } \\
\text { SHOTSHELL } \\
\text { SMALL PISTOL } \\
\text { SMALL RIFLE }\end{array}$ & $\begin{array}{l}\text { STD MAN } \\
20 \mathrm{kV} / 600 \mathrm{pF} \\
120 \mathrm{~mJ} \\
0 \\
X \\
X \\
0 \\
0 \\
0 \\
0 \\
0 \\
0 \\
0\end{array}$ & $\begin{array}{l}\text { STD MAN } \\
24.5 \mathrm{kV} / 1200 \mathrm{pF} \\
360 \mathrm{~mJ} \\
0 \\
* \\
* \\
0 \\
0 \\
0 \\
X \\
0 \\
0 \\
0\end{array}$ & $\begin{array}{l}\text { SEVERE } \\
25 \mathrm{kV} / 410 \mathrm{pF} \\
128 \mathrm{~mJ} \\
0 \\
X \\
0 \\
0 \\
0 \\
0 \\
X \\
0 \\
0 \\
0\end{array}$ & $\begin{array}{l}\text { SEVERE } \\
30 \mathrm{kV} / 410 \mathrm{pF} \\
185 \mathrm{~mJ} \\
0 \\
X \\
X \\
0 \\
0 \\
0 \\
X \\
0 \\
\text { X000 } \\
0\end{array}$ \\
\hline$X=F I R E$ (fail) & $*=\mathrm{NC}$ & TED & & \\
\hline
\end{tabular}


The primers that showed definite sensitivity are the $20 \mathrm{~mm}$ electric, $30 \mathrm{~mm}$ percussion, and large rifle electric primers. To provide additional threshold information, these devices were all evaluated using the Neyer[6] sensitivity approach. Tests were performed with the SSET for the large rifle electric and the $30 \mathrm{~mm}$ percussion primers. There were not enough samples to test the $20 \mathrm{~mm}$ electric primer to the SSET threat. All three primers were tested with the SMT; however, the total capacitance was decreased to 100 picofarads (PF) because, in the standard configuration, the SMT could not be operated at a voltage low enough to prevent initiation. Thus, to lower the total energy delivered a smaller capacitor was used. As with comparison between the SMT and SSET results, this modification of the capacitance makes direct correlation difficult. A summary of the Neyer results for the two simulators is presented in Tables 3 and 4, the associated measurements are documented in Tables 5 through 9.

Table 3.

Neyer Sensitivity Resuits Summary for Large Rifle Electric and $30 \mathrm{~mm}$ Percussion Primer Severe Human Body ESD Simulator

\begin{tabular}{|c|c|c|c|c|}
\hline $\begin{array}{l}\text { Primer } \\
\text { Type }\end{array}$ & $\begin{array}{l}\text { 50\% Energy } \\
\text { Threshold" }\end{array}$ & $\begin{array}{l}\text { Energy } \\
\text { Threshold } \\
\text { Sigma }\end{array}$ & $\begin{array}{l}50 \% \text { Charging } \\
\text { Voltage } \\
\text { Threshold }\end{array}$ & $\begin{array}{l}\text { Voltage } \\
\text { Threshold } \\
\text { Sigma }\end{array}$ \\
\hline $\begin{array}{l}30 \mathrm{~mm} \\
\text { Percussion }\end{array}$ & $610 \mu \mathrm{J}$ & $10 \mu \mathrm{J}$ & $3488 v$ & $188 \mathrm{v}$ \\
\hline Rifle Electric & $24.4 \mu \mathrm{J}$ & $10 \mu \mathrm{J}$ & $345 v$ & $277 v$ \\
\hline
\end{tabular}

It is clear when reviewing Tables 3 and 4 that the $20 \mathrm{~mm}$ electric, $30 \mathrm{~mm}$ percussion, and the large rifle electric primers are very sensitive to HBESD. All voltage levels are less than 5,000 volts, which is easily achievable under routine conditions[3]. The $30 \mathrm{~mm}$ percussion primer may not represent a true safety hazard because the stress was delivered to the interior of the device, which is very unlikely in normal applications. However, tests were not performed on this or any other primers where the discharge was delivered to the primer case. Given the potentially high sensitivity of the $30 \mathrm{~mm}$ percussion primer, a hazard may exist. Additional tests are required to resolve this issue. 
Table 4.

Neyer Sensitivity Results Summary

for $20 \mathrm{~mm}$ Electric, Large Rifle Electric and $30 \mathrm{~mm}$ Percussion Primers

Standard Human Body ESD Simulator, MODIFIED to $100 \mathrm{pF}$

Primer

Type

$20 \mathrm{~mm}$

Electric

$30 \mathrm{~mm}$

Percussion

Large

Electric

Rifle

$\begin{array}{ll}\text { 50\% Energy } & \text { Energy } \\ \text { Threshold } & \text { Threshold } \\ & \text { Sigma) }\end{array}$

$24.6 \mu \mathrm{J}$

$850 \mu \mathrm{J}$

$77 \mu \mathrm{J}$

$4 \mu \mathrm{J}$

$1247 v$

2036v

$100 \mu \mathrm{J}$

$\begin{array}{ll}50 \% \text { Charging } & \text { Voltage } \\ \text { Voltage } & \text { Threshold } \\ \text { Threshold } & \text { Sigma }\end{array}$

$831.7 v$

$71.9 v$

$717 v$

$313 v$

* Total Energy Stored in Tester Capacitive Discharge Circuit

The electric primers are clearly sensitive. In these cases, ESD levels of energy can be injected into the device via the electrical connection. This is not an unusual condition. These devices should be considered very sensitive to any ESD environment and possibly to other electrical hazards.

Table 5.

ESD Neyer Sensitivity Results for $30 \mathrm{~mm}$ Percussion Primer, Severe Human Body Tester

$\begin{array}{lllll}\begin{array}{l}\text { Primer } \\ \text { Type }\end{array} & \begin{array}{l}50 \% \text { Energy } \\ \text { Threshold* }\end{array} & \begin{array}{l}\text { Energy } \\ \text { Threshold } \\ \text { Sigma }\end{array} & \begin{array}{l}50 \% \text { Charging } \\ \text { Voltage } \\ \text { Threshold }\end{array} & \begin{array}{l}\text { Voltage } \\ \text { Threshold } \\ \text { Sigma }\end{array} \\ 30 \mathrm{~mm} & 610 \mu \mathrm{J} & 10 \mu \mathrm{J} & 3488 \mathrm{v} & 188 \mathrm{v}\end{array}$

- Total Energy Stored in Tester Capacitive Discharge Circuit 
Table 6.

ESD Neyer Sensitivity Results

for Large Rifle Electric Primer, Severe Human Body Tester

\begin{tabular}{lllll}
$\begin{array}{l}\text { Primer } \\
\text { Type }\end{array}$ & $\begin{array}{l}50 \% \text { Energy } \\
\text { Threshold* }\end{array}$ & $\begin{array}{l}\text { Energy } \\
\text { Threshold } \\
\text { Sigma }\end{array}$ & $\begin{array}{l}50 \% \text { Charging } \\
\text { Voltage } \\
\text { Threshold }\end{array}$ & $\begin{array}{l}\text { Voltage } \\
\text { Threshold } \\
\text { Sigma }\end{array}$ \\
$\begin{array}{l}\text { Large } \\
\text { Rifle } \\
\text { Electric }\end{array}$ & $24.4 \mu \mathrm{J}$ & $10 \mu \mathrm{J}$ & $345 \mathrm{v}$ & $227 \mathrm{v}$ \\
\hline
\end{tabular}

- Total Energy Stored in Tester Capacitive Discharge Circuit

Table 7.

ESD Neyer Sensitivity Results

for $20 \mathrm{~mm}$ Electric Primer, Standard Man Tester

(100 pF Modification)

$\begin{array}{lllll}\begin{array}{l}\text { Primer } \\ \text { Type }\end{array} & \begin{array}{l}50 \% \text { Energy } \\ \text { Threshold* }\end{array} & \begin{array}{l}\text { Energy } \\ \text { Threshold } \\ \text { Sigma }\end{array} & \begin{array}{l}50 \% \text { Charging } \\ \text { Voltage } \\ \text { Threshold }\end{array} & \begin{array}{l}\text { Voltage } \\ \text { Threshold } \\ \text { Sigma }\end{array} \\ \begin{array}{l}20 \mathrm{~mm} \\ \text { Electric }\end{array} & 24.6 \mu \mathrm{J} & 0.3 \mu \mathrm{J} & 831.7 \mathrm{~V} & 71.9 \mathrm{~V}\end{array}$

* Total Energy Stored in Tester Capacitive Discharge Circuit

Table 8.

ESD Neyer Sensitivity Results

for $\mathbf{3 0}$ mm Percussion Primer, Standard Man Tester

(100 pF Modification)

Primer

Type

$30 \mathrm{~mm}$

Percussion
$50 \%$ Energy

Threshold"

$850 \mu \mathrm{J}$

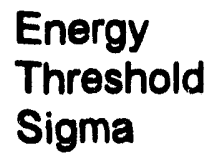

Sigma

$100 \mu \mathrm{J}$
$50 \%$ Charging

Voltage

Threshold

2036v

$717 v$

* Total Energy Stored in Tester Capacitive Discharge Circuit 
Table 9.

ESD Neyer Sensitivity Results

for Large Rifle Electric Primer, Standard Man Tester

(100 pF Modification)

\begin{tabular}{lllll}
$\begin{array}{l}\text { Primer } \\
\text { Type }\end{array}$ & $\begin{array}{l}50 \% \text { Energy } \\
\text { Threshold* }\end{array}$ & $\begin{array}{l}\text { Energy } \\
\text { Threshold } \\
\text { Sigma }\end{array}$ & $\begin{array}{l}50 \% \text { Charging } \\
\text { Voltage } \\
\text { Threshold }\end{array}$ & $\begin{array}{l}\text { Voltage } \\
\text { Threshold } \\
\text { Sigma }\end{array}$ \\
$\begin{array}{l}\text { Large } \\
\begin{array}{l}\text { Rifle } \\
\text { Electric }\end{array}\end{array}$ & $77 \mu \mathrm{J}$ & $4 \mu \mathrm{J}$ & $1247 \mathrm{v}$ & $313 \mathrm{v}$ \\
\hline
\end{tabular}

- Total Energy Stored in Tester Capacitive Discharge Circuit

Section 8: Conclusions

This investigation was undertaken to determine whether a specified group of powders and primers were sensitive to an HBESD threat as specified by Sandia Specifications SS302.365-000[2] and SS392498-000[3] and if potential safety hazards exist during haridling oi these devices/materials. From the information presented in this document, it may be possible to address specific safety issues concerning handling of these devices and materials; however, additional information is required to definitively resolve such concerns. Necessary information includes a survey of the areas where the devices/materials are handled to assess the threat. It also includes an evaluation of the mitigating features that are present or could be installed. Additional testing to obtain -tatistically significant data, where required, and/or address possible variations in sensitivity thresholds due to in-situ configurations and conditions may also be required.

Specifically, the results of this investigation show that the tested powders are not sensitive to the human body ESD environment. Some of the primers are definitely sensitive. The insensitivity of the powders is based on very limited sample size and on a unique test configuration that may not be applicable to the in-situ environment.

Tests of the percussion primers generally show a eansitivity. The test configuration of injecting the spark into the interior of the primer is highly unlikely in an actual environment. The device may be insensitive due to its physical configuration of being enclosed in a metal case. Given this consideration, it is still evident that the materials used in some of these primers are very seinsitive. It is possible, although unlikely, that 
a spark discharge to the exterior primer case might result in an initiation. This configuration was not investigated and requires additional tests to resolve the issues.

The electric primers showed very high-sensitivity levels (i.e., 345 volts, $24.4 \mu \mathrm{J}$, severe human body). These devices are intended to be initiated by low-level electrical signals and they do meet that requirement. As a result, they should be considered as ESD sensitive; a 345-volt , $24.4 \mu \mathrm{J}, \mathrm{HBESD}$ is readily achieved under most conditions.

In general, the data acquired in this investigation should reinforce the notion of extreme caution when using explosives. Although inconvenient, cotton clothing, ground straps, and other mitigation techniques would be prudent until additional in-depth sensitivity tests and facility surveys are performed. Better still, treat all energetics as if they were sensitive and avoid any mistakes in distraction. 
Section 9: References

1. Environmental Safety and Health Manual, MN47101, Cage Code 14213, Chapter 9, Section E, Sandia National Laboratories, Albuquerque, NM

2. Test Specification, Electrostatic Sensitivity, SS302365-000, Issue D, Cage Code 14213, ACO 852274MD-C, Revision 1, Sandia National Laboratories, Albuquerque, NM, May 27, 1986

3. Test Specification, Testing Electrostatic Discharge, Electro-explosive Devices, SS392498-000, Issue C, Cage Code 14213, CER920488SA, Sandia National Laboratories, Albuquerque, NM, August 6, 1993

4. L. J. Heilman, Establishment of Criteria for Electrostatic Sensitivity of Explosive Devices, Sandia National Laboratories memorandum to J. C. King, September 11, 1973,

5. R. J. Fisher, The Electro-Static Discharge Threat Environment Data Base and Recommended Baseline Stockpile-to-Target Sequence Specifications, SAND88-2658, Sandia National Laboratories, Albuquerque, NM, November 1988

6. Barry Neyer, Sensitivity Test and Analysis Software, Barry Neyer Software, 1989

7. Louis J. Montesi, The Development of a Fixed Gap Electro-static Spark Discharge Apparatus For Characterizing Explosives, in 6th Symposium on ElectroExplosives, held at Franklin Institute Research Laboratories, San Francisco, CA, July 8-10, 1969. 
Appendix A $-29 / 30-$ 


\section{Sandia National Laboratories}

Albuquerque, Now Mexico 87185

date.

from:

subject:

Division 1543 would like Division 2514 to Electro-Static Discharge (ESD) test three different propellants and three different percussion primers. The propellants are 3"-50 ( $3 \mathrm{~mm}$ by $1 / 2$ inch, seven-perforation triple base chordite), $20 \mathrm{~mm}$ powder $(0.5 \mathrm{~mm}$ by $1 / 8$ inch single-perforation double base powder), and an IMR-4064 (single base powder). The primers are a $30 \mathrm{~mm}$ primer, a $45-70$ primer and a 50 caliber primer.

Division 7531 would like Division 2514 to ESD test four different percussion primers and two different propellants. The propellants are BKNO3 powder and a fine grind $4 \mathrm{~F}$ black powder. The percussion primers are a small rifle, small pistol, large rifle, and large pistol primers.

The tests will be performed on the Sandia Standard Man Model (Body model only) as defined in the Safety Manual. A comparison vill be done on the Severe Human Body Model ESD tester. This tester is the hand/body model.

It is proposed that the propellants and primers be tested to the standard ESD conditions and a determination made if the material was initiated or not. This test would consist of testing one (1) sample, one discharge pulse per sample for each of the Standard Man Model and one (1) sample, one discharge pulse per sample for the Severe Human Body Model.

A failure for the test is defined as a sample that has significant damage (a burn of the powder, or a firing of the primer). SS302366-000 (ESD test specification) defines a failure as any device (powder) that initiates when subjected to the test pulse. The test pulse is $20 \mathrm{kV}$ (600 picofarad) through a $500 \mathrm{ohm}$ series resistor, and stray capacitance of the discharge circuit including fixture shall not exceed 50 pF.

Once the baseline (standard testing) has been established as a go, no-go, test, it is proposed that the voltage (and subsequently, the current) be varied to determine the $50 \%$ fire/no-fire point for the samples. This would be accomplished by using a 
Bruceton, Neyer or Langlie type program to determine the instrument setting for testing, and would also minimize the number of samples.

The testing would be accomplished by building a fixture to hold the powder and/or primers. This means that primer dimensions would be necessary and the primers be removed from the shells. The upper electrode will be placed in contact with the powders, as this will prevent us from having to machine the powders. This would be accomplished by building a fixture using a needle for the upper electrode, sparking across an air gap (powder or primer gap) to a steel cylinder ( 0.75 inch diameter by 0.75 inches in length) as the base electrode. A phenolic sleeve would be glued to the base electrode (or a grove cut in the base electrode) to contain the sample.

The tests would be conducted as follows.

$\begin{array}{lllll} & \text { \#STAND } & \text { \#SEVERE } & \begin{array}{l}\text { \#50\% } \\ \text { STAND } \\ \text { MAN }\end{array} & \begin{array}{l}\text { \#50\% } \\ \text { SEVERE }\end{array} \\ \text { 3" - POWDER } & 1 & 1 & 15 & 15 \\ \text { 20 mm POWDER } & 1 & 1 & 15 & 15 \\ \text { IMR-4064 POWDER } & 1 & 1 & 15 & 15 \\ \text { BKNO3 POWDER } & 1 & 1 & 15 & 15 \\ \text { BLACK POWDER } & 1 & 1 & 15 & 15 \\ \text { 30 mm PRIMER } & 1 & 1 & 15 & 15 \\ \text { 45-70 PRIMER } & 1 & 1 & 15 & 15 \\ \text { 50 CALIBER PRIMER } & 1 & 1 & 15 & 15 \\ \text { SMALL RIFLE PRIMER } & 1 & 1 & 15 & 15 \\ \text { SMALL PISTOL PRIMER } & 1 & 1 & 15 & 15 \\ \text { LARGE RIFLE PRIMER } & 1 & 1 & 15 & 15 \\ \text { LARGE PISTOL PRIMER } & 1 & 1 & 15 & 15\end{array}$

A total of 384 samples to be tested.

The results will be given in joules (or millijoules) for the $50 \%$ threshold for the Sandia Standard Man and the Severe Human Body Model tests. This will be calculated by $0.5^{\text {"C }} \mathrm{V}^{\mathrm{V} V} \mathrm{~V}$. Current versus time records will be kept for the single tests onily. The single tests will also be recorded as a go, or no-go, for the standard tests. The remaining statistical samples will be reported in tabular form: energy versus go, or nogo. The voltage, capacitance, and maximum current achieved will also be recorded in tabular form for each test.

Documentation (pictures, schematics of fixtures, etc.) will be provided for the set-up and testing procedures as part of the final report. 


\section{RBB:2514}

Distribution:

1543 C. H. Konrad (X4-6977, Case 0006.020)

7531 K. D. Svensson (X4-8809, Case 0748.300)

2514 L. L. Bonzon

2514 J. C. Lanoue

Copy to:

2514 R. B. Berry

2514 Day File 
Distribution:

$\begin{array}{llll}10 & \text { MS0100 } & 7613-2 & \text { Document Processing for DOE/OSTI } \\ 1 & \text { MS0326 } & 02653 & \text { F. H. Braaten, Jr. } \\ 1 & \text { MS0326 } & 2653 & \text { M. C. Grubelich } \\ 1 & \text { MS0327 } & 02654 & \text { L. L. Bonzon } \\ 10 & \text { MS0327 } & 02654 & \text { R. B. Berry } \\ 5 & \text { MS0327 } & 02654 & \text { T. A. Broyles } \\ 1 & \text { MS0327 } & 02654 & \text { J. C. Lanoue } \\ 1 & \text { MS0329 } & 02652 & \text { J. G. Harlan } \\ 1 & \text { MS0329 } & 2652 & \text { T. M. Massis } \\ 1 & \text { MS0619 } & 7151 & \text { Technical Publications } \\ 1 & \text { MS0633 } & 12363 & \text { D. A. Clements } \\ 1 & \text { MS0633 } & 12363 & \text { J. N. Middleton } \\ 1 & \text { MS0821 } & 1433 & \text { C. H. Konrad } \\ 1 & \text { MS0821 } & 1433 & \text { P. L. Stanton } \\ 1 & \text { MS0865 } & 2753 & \text { M. E. Morris } \\ 1 & \text { MS0865 } & 2753 & \text { J. R. Barnum } \\ 5 & \text { MS0899 } & 7141 & \text { Technical Library } \\ 1 & \text { MS1135 } & 2761-6 & \text { K. D. Svensson } \\ 1 & \text { MS1135 } & 2761-6 & \text { T. L. Workman } \\ 1 & \text { MS9018 } & 8523-2 & \text { Central Technical Files }\end{array}$




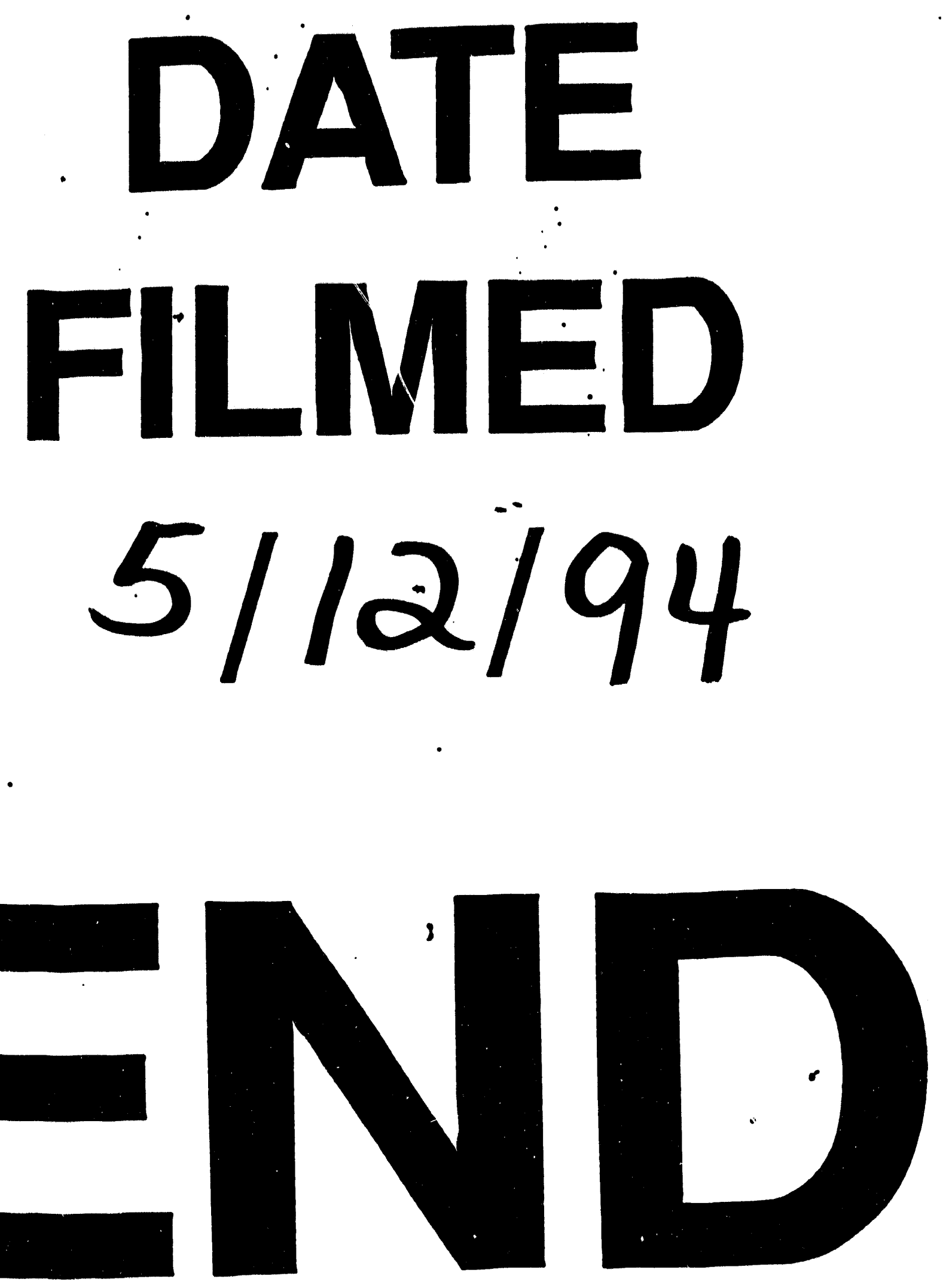


